\title{
The Importance of Incorporating OCT2 Plasma Membrane Expression and Membrane Potential in IVIVE of Metformin Renal Secretory Clearance ${ }^{\mathbb{S}}$
}

\author{
Vineet Kumar, Jia Yin, Sarah Billington, Bhagwat Prasad, Colin D. A. Brown, Joanne Wang, \\ and Jashvant D. Unadkat
}

Department of Pharmaceutics, University of Washington, Seattle, Washington (V.K., J.Y., B.P., J.W., J.D.U.) and Institute for Cell and Molecular Biosciences, Newcastle University, Newcastle upon Tyne, United Kingdom (S.B., C.D.A.B.)

Received May 12, 2018; accepted August 3, 2018

\section{ABSTRACT}

Transporter expression, determined by quantitative proteomics, together with PBPK models is a promising approach for in vitro-to-in vivo extrapolation (IVIVE) of transporter-mediated drug clearance. OCT2expressing HEK293 and MDCKII cells were used to predict in vivo renal secretory clearance $\left(\mathrm{CL}_{r, \mathrm{sec}}\right)$ of metformin. $\left[{ }^{14} \mathrm{C}\right]-$ Metformin uptake clearance in ОСТ2-expressing cells was determined and scaled to in vivo $C L_{r, s e c}$ by using OCT2 expression in the cells versus the human kidney cortex. Through quantitative targeted proteomics, the total expression of OCT2 in HEK293, MDCKII cells, and human kidney cortex was $369.4 \pm 26.8,19 \pm 1.1$, and $7.6 \pm 3.8 \mathrm{pmol} / \mathrm{mg}$ cellular protein, respectively. The expression of ОСТ2 in the plasma membrane of
HEK293 and MDCKII cells, measured using an optimized biotinylation method followed by quantitative proteomics, was $30.2 \%$ and $51.6 \%$, respectively. After correcting for percent of OCT2 expressed in the plasma membrane and the resting membrane potential (millivolts) difference between the OCT2-expressing cells and the renal epithelial cells, the predicted $\mathrm{CL}_{\mathrm{r}, \mathrm{sec}}$ of metformin was $250.7 \mathrm{ml} / \mathrm{min}$, a value within the range of the observed $\mathrm{CL}_{r, s e c}$ of metformin. These data demonstrate the promise of using quantitative proteomics for IVIVE of transportermediated drug clearance and highlight the importance of quantifying plasma membrane expression of transporters and utilizing cells that mimic the in vivo mechanism(s) of transport of drugs.

\section{Introduction}

Transporters play an important role in drug absorption, distribution, and elimination. When a drug under development or its active/toxic metabolite(s) has significant renal clearance, prediction of its in vivo renal clearance from in vitro studies (IVIVE) is important to predict the first in human dose, systemic clearance of the drug, renal drug-drug interaction, and kidney epithelial cell drug concentrations. While the filtration clearance of a drug can readily be predicted from the average glomerular filtration rate and the fraction of drug unbound in the plasma, IVIVE of the renal secretory clearance of a drug is challenging. While allometry (Paine et al., 2011) or quantitative structure-activity relationship (Dave and Morris, 2015) have been used to predict the renal clearance of drugs, these methods do not account for involvement of transporters and therefore lack the ability to predict in vivo transportermediated renal secretory clearance $\left(\mathrm{CL}_{\mathrm{r}, \mathrm{sec}}\right)$ or renal transportermediated drug-drug interactions. Although tools (e.g., primary kidney epithelial cells) to predict $\mathrm{CL}_{\mathrm{r}, \mathrm{sec}}$ of a drug are becoming available, their predictive abilities have yet to be tested. Thus, alternate methods are needed to predict $\mathrm{CL}_{\mathrm{r}, \mathrm{sec}}$ of a drug. We (Ishida et al., 2018), and others

V.K. was supported by the Simcyp Grant \& Partnership Scheme. This study is supported in part by National Institutes of Health National Institute on Drug Abuse [Grant P01-DA032507] and National Institute of General Medical Sciences [Grant R01-GM066233].

https://doi.org/10.1124/dmd.118.082313.

S This article has supplemental material available at dmd.aspetjournals.org.
(Bosgra et al., 2014; Vildhede et al., 2016) have shown that transport activity of a drug in cell lines overexpressing the transporter(s) of interest can be used to predict transporter-mediated drug clearance if a scaling factor to account for differences in transporter expression in the cell line and in the tissue (e.g., kidneys) is considered. Theoretically, since it is the transporters at the plasma membrane that are responsible for the cellular uptake and/or efflux of drugs, quantifying such expression may improve IVIVE of drug clearance (Kumar et al., 2017). Therefore, as a proof of concept, the goals of our study were to determine 1) if transporter-mediated in vivo $\mathrm{CL}_{\mathrm{r}, \mathrm{sec}}$ of metformin can be predicted within the range of the observed values using protein expression and transport activity of organic cation transporter 2 (OCT2) in OCT2expressing cell lines (HEK293 and MDCKII) as well as OCT2 protein expression in the human kidney cortex and 2) whether this prediction could be improved by incorporating plasma membrane expression of OCT2-expressing cells and the membrane potential of these cells versus human renal epithelial cells. We chose metformin as our model drug as literature evidence suggests (see Discussion) that its $\mathrm{CL}_{\mathrm{r}, \mathrm{sec}}$ is determined primarily by OCT2.

\section{Materials and Methods}

Chemicals and Reagents

Synthetic signature peptides for OCT2 were obtained from New England Peptides (Boston, MA). The corresponding stable isotope labeled (SIL) peptides for OCT2 and $\mathrm{Na}^{+}-\mathrm{K}^{+}$ATPase, total protein quantification bicinchoninic acid assay (BCA) kit,

ABBREVIATIONS: BCA, bicinchoninic acid assay; DPBS, Dulbecco's phosphate-buffered saline; $\mathrm{CL}_{r, \text { sec }}$, renal secretory clearance; DTT, dithiothreitol; IVIVE, in vitro-to-in vivo extrapolation; KRH, Krebs-Ringer-HEPES; LC-MS/MS, liquid chromatography tandem mass spectrometry; OCT2, organic cation transporter 2; SIL, stable isotope labeled; sulfo-NHS-SS-Biotin, sulfosuccinimidyl-2-(biotinamido) ethyl-1, 3-dithiopropionate. 
dithiothreitol (DTT), iodoacetamide (IAA), mass spectrometry grade trypsin, Dulbecco's modified Eagles' medium (DMEM) high glucose medium (Gibco), Dulbecco's phosphate-buffered saline (DPBS), Krebs-Ringer-HEPES (KRH) buffer, and Pierce cell surface protein isolation kit were obtained from Thermo Scientific (Rockford, IL). Pierce cell surface protein isolation kit contains sulfosuccinimidyl-2(biotinamido) ethyl-1, 3-dithiopropionate (sulfo-NHS-SS-biotin), quenching solution (100 mM glycine), lysis buffer, neutravidin agarose gel, wash buffer, column accessory pack, DTT, phosphate buffer, and Tris buffer. Metformin [biguanido- $-{ }^{14} \mathrm{C}$ ] hydrochloride $(98 \mathrm{mCi} / \mathrm{mmol})$ was purchased from Moravek Biochemicals, Inc. (Brea, CA). ScintiVerse BD Cocktail liquid scintillant and HPLC-grade acetonitrile were purchased from Fischer Scientific (Fair Lawn, NJ). Cimetidine, metformin (hydrochloride salt), and formic acid were purchased from Sigma-Aldrich (St. Louis, $\mathrm{MO})$. All reagents were analytical grade.

\section{Human Kidney Cortex and Transporter-Expressing Cell Lines}

Transplant quality human kidney cortices (for demographics, see Supplementry Table $2 S$ in Prasad et al., 2016) were obtained from Newcastle University, England ( $n=5$, randomly selected). OCT2-expressing HEK293 and MDCKII cells were created as described previously (Yin et al., 2015, 2016).

\section{Measurement of OCT2 Transporter Uptake Activity in HEK293 and MDCKII Cells}

Transport studies were conducted in OCT2-expressing MDCKII and HEK293 cells with $\left[{ }^{14} \mathrm{C}\right]$-metformin with or without $1 \mathrm{mM}$ cimetidine (OCT2 inhibitor). For transport assays, OCT2-expressing MDCKII and HEK293 cells were grown in 24-well poly-D-lysine coated plates, at a density of 75,000 cells per well with $1 \mathrm{ml}$ of high glucose Dulbecco's modified Eagles' medium (changed daily). On day 3 , cells were washed with $1 \mathrm{ml} /$ well Dulbecco's phosphate-buffered saline buffer and incubated at $37^{\circ} \mathrm{C}$ with KRH buffer (5.6 mM glucose, $125 \mathrm{mM} \mathrm{NaCl}, 4.8 \mathrm{mM} \mathrm{KCl}, 1.2 \mathrm{mM} \mathrm{KH}_{2} \mathrm{PO}_{4}$, $1.2 \mathrm{mM} \mathrm{CaCl}_{2}, 1.2 \mathrm{mM} \mathrm{MgSO}_{4}$, and $25 \mathrm{mM}$ HEPES) containing $5.5 \mu \mathrm{M}$ $\left[{ }^{14} \mathrm{C}\right]$-metformin with or without $1 \mathrm{mM}$ cimetidine (OCT2 inhibitor). After 2 minutes (when uptake is linear), the uptake (in triplicate) was terminated by washing the cells three times with ice-cold KRH buffer ( $1 \mathrm{ml}$ each). Then, the cells were lysed with $0.5 \mathrm{ml} 1 \mathrm{M} \mathrm{NaOH}$ at $37^{\circ} \mathrm{C}$ for 2 hours and neutralized with $0.5 \mathrm{ml} 1 \mathrm{M} \mathrm{HCl}$. Thirty microliters of this lysate solution was used for total protein estimation using the BCA method, and $200 \mu \mathrm{l}$ was used to analyze total radioactivity by Tri-Carb Liquid Scintillation Counters (PerkinElmer, Waltham (MA)). OCT2-mediated uptake was determined by the difference in the metformin uptake in the presence/absence of $1 \mathrm{mM}$ cimetidine. The in vitro OCT2-mediated clearance of metformin was calculated as the ratio of OCT2mediated uptake and metformin concentration in the media.

\section{LC-MS/MS Quantification of Total OCT2 Expression in Human Kidney Cortex as Well as Total and Plasma Membrane OCT2 Expression in HEK293 and MDCKII Cells}

Plasma Membrane Isolation from OCT2-expressing HEK293 and MDCKII Cells. Plasma membranes from OCT2-expressing HEK293 and MDCKII cells were isolated in three and two independent experiments, respectively, using a biotinylation methodology optimized in our laboratory (Kumar et al., 2017). Briefly, HEK293 and MDCKII cells were grown in $75 \mathrm{~cm}^{2}$ flasks until $80 \%-100 \%$ confluency and incubated with $10 \mathrm{ml}$ of $0.78 \mathrm{mg} / \mathrm{ml}$ of sulfo-NHS-SS-biotin at $37^{\circ} \mathrm{C}$ for 1 hour to biotinylate extracellular free primary amines (lysine or arginine) or $\mathrm{N}$-terminal primary amines of extracellular peptide residues in the plasma membrane. After cell lysis, biotinylated plasma membranes were isolated using neutravidin resin columns.

Determination of Percent Plasma Membrane Expression of OCT2 in OCT2-expressing Cells. The expression of OCT2, $\mathrm{Na}^{+}-\mathrm{K}^{+}$-ATPase, and calreticulin in the lysate, the nonbiotinylated and the biotinylated fractions was quantified using LC-MS/MS (see below). Stable labeled internal standards of OCT2 and $\mathrm{Na}^{+}-\mathrm{K}^{+}$-ATPase unique peptides were used to determine the area ratio (analyte:SIL ratio) of the respective peaks in the samples obtained from the biotinylation experiment. For calreticulin, the stable labeled internal standard was not available, and therefore the stable labeled internal standard of $\mathrm{Na}^{+}-\mathrm{K}^{+}$-ATPase was used to estimate the calreticulin peak area ratio (Kumar et al., 2017).
OCT2 Total Protein Quantification in Kidney Cortex. Sample preparation and quantitative proteomics were performed as described previously (Prasad et al., 2016). Total protein content (wt/wt) in kidney cortex homogenate was quantified by BCA assay. OCT2 expression was determined in triplicate for each kidney cortex homogenate. Briefly, $20 \mu \mathrm{l}$ of $2.0 \mathrm{mg} / \mathrm{ml}$ (or lower concentration) of the human kidney cortex or transporter-expressing cell line or samples obtained through biotinylation experiments was treated with $15 \mu \mathrm{l}$ of ammonium bicarbonate buffer (50 mM, pH 7.8), $18 \mu \mathrm{l}$ of $3 \%$ sodium deoxycholate (wt/v), $6 \mu 1$ DTT $(100 \mathrm{mM})$, and $10 \mu \mathrm{l}$ of human albumin $(10 \mathrm{mg} / \mathrm{ml})$. Proteins present in the sample were denatured, and disulfide bond between cysteine residues was reduced by incubation at $95^{\circ} \mathrm{C}$ for 5 minutes, followed by the addition of $6 \mu \mathrm{l}$ of iodoacetamide $(200 \mathrm{mM}$; an alkylating agent) and treatment with ice-cold methanol $(0.5 \mathrm{ml})$, chloroform $(0.2 \mathrm{ml})$, and water $(0.45 \mathrm{ml})$ and centrifugation. Lastly, the protein sample was digested with $20 \mu \mathrm{l}$ of trypsin followed by centrifugation at $5000 \mathrm{~g}$ for 5 minutes at $4{ }^{\circ} \mathrm{C}$, and $5 \mu \mathrm{l}$ of the supernatant was introduced into the LC-MS/MS system. The calibration standards were prepared by spiking peptide standards into the extraction buffer II of the membrane protein extraction kit. Samples were analyzed as described before by Kumar et al. (2017). Briefly, AB Sciex 6500 triple-quadrupole mass spectrometer (Sciex, Framingham, MA) coupled to the Water Acquity UPLC system (Waters Corporation, Milford, MA) was operated in electrospray positive ionization mode for liquid chromatography-tandem mass spectroscopy (LC-MS/MS) analysis of the signature peptides (Supplemental Table 1). The transitions from doubly charged parent ion to singly charged product ions for the analyte peptides and their respective SIL peptides were monitored (Supplemental Table 1). The chromatographic separation and resolution were obtained on an Acquity UPLC HSS T3 Column, $(1.8 \mu \mathrm{m}, 2.1 \times 100 \mathrm{~mm})$ with a $0.2 \mu \mathrm{m}$ inlet frits (Waters). Mobile phases $(0.3 \mathrm{ml} / \mathrm{min})$ consisted of $0.1 \%$ formic acid in water (A) and $0.1 \%$ formic acid in acetonitrile (B). The gradient program for UPLC method for determination of OCT2 in human kidney cortex and OCT2-expressing HEK293 and MDCKII cells was: 0-2 minutes: $3 \% \mathrm{~B}$; $2-20$ minutes: $3 \%-45 \% \mathrm{~B} ; 20$ 23 minutes: $45 \%-90 \%$ B; 23 to 24 minutes: $90 \%$ B; $24-24.5$ minutes: $90 \%-3 \% \mathrm{~B}$; 24.5-28 minutes: $3 \%-3 \% \mathrm{~B}$ including washing and re-equilibration for $3.5 \mathrm{~min}-$ utes. Seven calibration standards ranging from 0.14 to $70.4 \mathrm{fmol}$ (on the column) were used to quantify OCT2.

\section{Prediction of Metformin In-Vivo $\mathbf{C L}_{\mathbf{r}, \text { sec }}$.}

Metformin in vivo $\mathrm{CL}_{\mathrm{r} \text {,sec }}$ was scaled from experimentally determined metformin in-vitro clearance by using the expression of OCT2 in expressed cells and human kidney cortex (eq. 1, Table 1) and the plasma membrane potential difference between HEK293/MDCKII cells and human renal epithelial cells. To do so, we made the following assumptions: 1) OCT2-mediated metformin uptake into the human kidney is the rate determining step in metformin's $\mathrm{CL}_{\mathrm{r}, \mathrm{sec}}, 2$ ) in vivo, OCT2 is expressed entirely in the plasma membrane of human kidney renal epithelial cells (Fisel et al., 2016), and 3) the human kidney cortex is $70 \%$ of total kidney by weight (Bouchet et al., 2003). In addition, we experimentally determined the total protein content in the human kidney cortex homogenate (wt/wt). Therefore:

$$
\begin{aligned}
\mathrm{CL}_{\mathrm{r}, \text { sec }}= & 2 \text { (due to } 2 \text { kidneys }) \times \mathrm{CL}_{\text {in vitro }} \times \frac{[E] \text { in vivo }}{[E] \text { in vitro }} \times \text { cortex weight } \\
& \times \text { Total tissue protein per unit cortex weight }
\end{aligned}
$$

Where $[E]=$ Total OCT2 expression in human kidneys (in vivo) and in OCT2expressing cells (in vitro), respectively. Total tissue protein per unit cortex weight was estimated by the BCA assay.

The OCT2 total cell expression-based predicted metformin $\mathrm{CL}_{\mathrm{r}, \mathrm{sec}}$ was corrected as follows: 1 ) the percent of OCT2 expressed in the plasma membrane in OCT2-expressing cells and 2) the difference in plasma membrane potential between HEK293/MDCKII cells and human renal epithelial cells. The latter was based on the observations by Burt et al. (2016) and Koepsell and Keller (2016). The rate of OCT2-mediated metformin transport was directly proportional to the difference in electrochemical driving force across the plasma membrane of OCT2-expressing cells and kidney epithelial cells (Burt et al., 2016; Koepsell and Keller, 2016). We assumed that both HEK293 and MDCKII cells had a similar resting membrane potential difference of $-35 \mathrm{mV}$ (see Discussion for details). Correcting for the twofold difference between the plasma membrane potential of 
TABLE 1

Values used for IVIVE of metformin $\mathrm{CL}_{\mathrm{r}, \mathrm{sec}}$

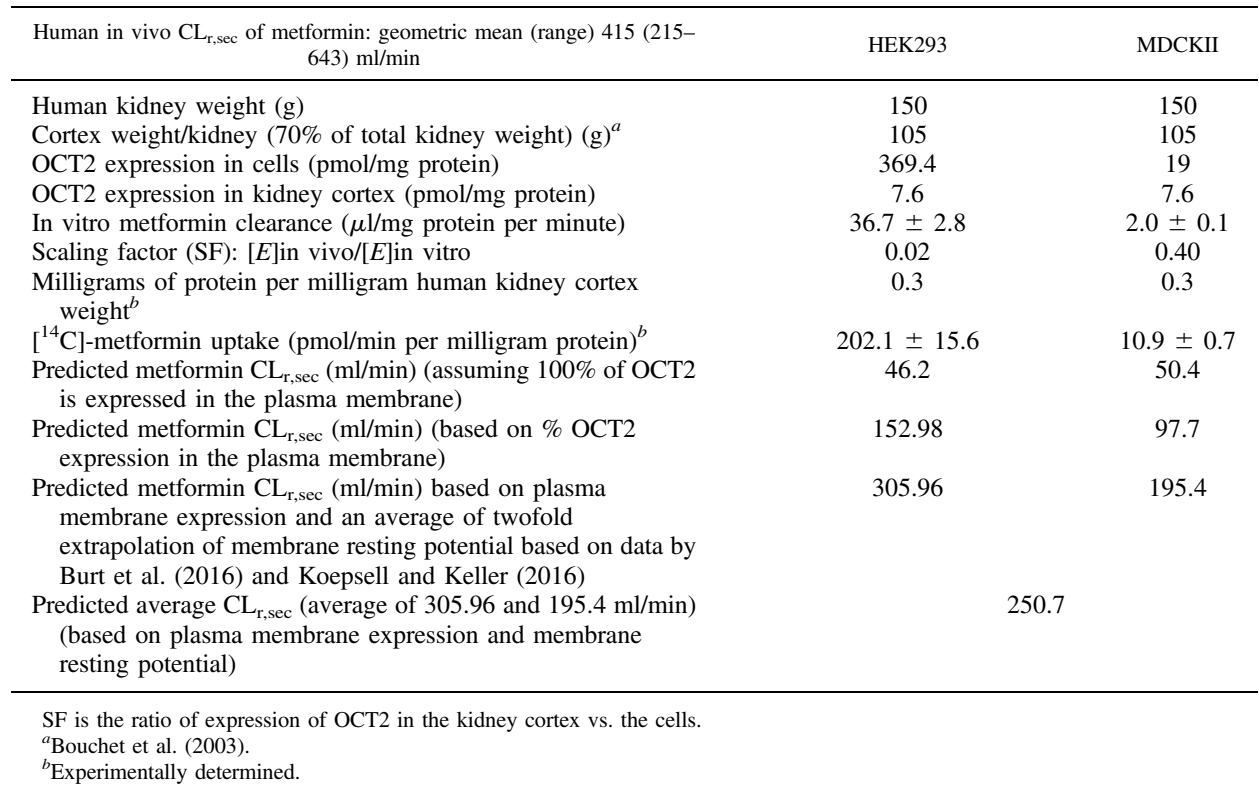

the OCT2-expressing cells $(-35 \mathrm{mV})$ and kidney epithelial cells $(-70 \mathrm{mV})$ resulted in a twofold correction of our predicted metformin $\mathrm{CL}_{\mathrm{r}, \mathrm{sec}}$

\section{Results}

OCT2-Mediated $\left[{ }^{14} \mathrm{C}\right]$-metformin Uptake Clearance in OCT2Expressing HEK293 and MDCKII Cells

$\left[{ }^{14} \mathrm{C}\right]$-metformin uptake clearance (mean \pm S.D.) was $36.7 \pm 2.8$ and $2.0 \pm 0.1 \mu \mathrm{l} / \mathrm{mg}$ cellular protein per minute $(n=3$ replicates from a single experiment) in HEK293 and MDCKII cells, respectively.

Total Expression of OCT2 in the Human Kidney Cortex and OCT2-Expressing HEK293 and MDCKII Cells

Total OCT2 expression (mean \pm S.D.) in the human kidney cortex, HEK293, and MDCKII cells was 7.6 $\pm 3.8,369.4 \pm 26.8$, and $19 \pm 1.1$ $\mathrm{pmol} / \mathrm{mg}$ protein, respectively (Fig. 1A; Table 1). Total protein content in human kidney cortex homogenate was $30 \% \mathrm{wt} / \mathrm{wt}$.

\section{Plasma Membrane Expression of OCT2 in OCT2-Expressing} HEK293 and MDCKII Cells

The percent of OCT2 expressed in the plasma membrane of OCT2expressing HEK293 and MDCKII cells was only $30.2 \pm 1.9$ and 51.6, respectively (Fig. 1B), while that of $\mathrm{Na}^{+}-\mathrm{K}^{+}$-ATPase (plasma membrane marker) was $58.8 \pm 3.6$ and 83.7 , respectively (Fig. 1B). The corresponding percent of calreticulin (endoplasmic reticulum marker) biotinylated was only $6.7 \pm 2.3$ and 11.1 , confirming minimal intracellular penetration of the sulfosuccinimidyl-2-(biotinamido) ethyl-1, 3-dithiopropionate (sulfo-NHS-SS-biotin) reagent (Fig. 1B)

\section{IVIVE of In Vivo $\mathrm{CL}_{\mathrm{r} \text {,sec }}$ of Metformin Based on OCT2 Expression as well as Resting Membrane Potential}

A literature review of human in vivo metformin renal clearance data from multiple studies resulted in a mean (geometric mean) $\mathrm{CL}_{\mathrm{r} \text {,sec }}$ (assuming $\mathrm{CL}_{\text {filtration }}$ is $120 \mathrm{ml} / \mathrm{min}$ ) of $415 \mathrm{ml} / \mathrm{min}$ (range 215-643 ml/min; Supplemental Table 2). Assuming 100\% of OCT2
A

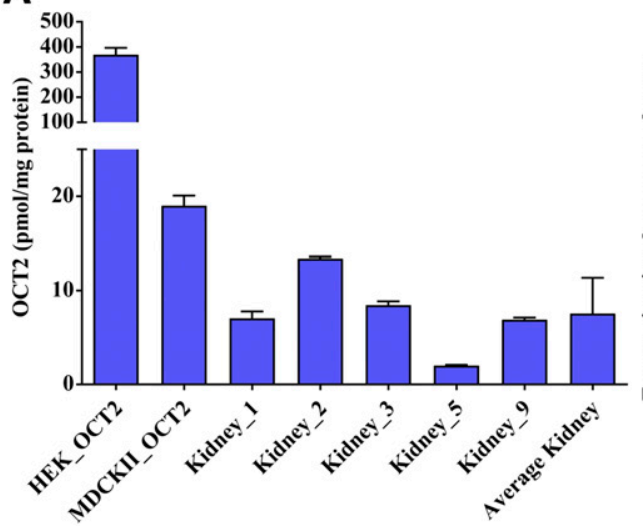

B

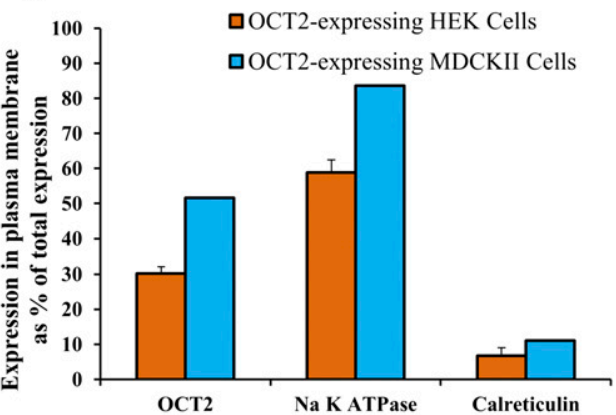

Fig. 1. Total cellular expression of OCT2 in human kidney cortex and OCT2-expressing HEK293 and MDCKII cells and plasma membrane expression of OCT2 in OCT2expressing HEK293 and MDCKII cells. (A) OCT2 expression in the human kidney cortex $(n=5)$, HEK293, and MDCKII cells was $7.6 \pm$ $3.9,369.4 \pm 26.8$, and $19 \pm 1.1 \mathrm{pmol} / \mathrm{mg}$ protein (mean \pm S.D. of triplicates of a single experiment). (B) The percent of total OCT2, $\mathrm{Na}^{+}-\mathrm{K}^{+}$-ATPase and calreticulin expressed in the plasma membrane of OCT2-expressing HEK293 (mean \pm S.D, $n=3$ independent experiments) was $30.2 \pm 1.9,58.8 \pm 3.6$, and $6.7 \pm 2.3$, respectively, while that in MDCKII (average of $n=2$ independent experiments) was 51.6, 83.7, and 11.1 respectively. Mass balance showed that the recovery of all proteins was $94.5 \%-114.4 \%$. Data are average of two and three independent experiments for OCT2expressing MDCKII and HEK293 cells, respectively. 
transporters are expressed in the plasma membrane of OCT2-expressing HEK293 and MDCKII cells, metformin's CL $_{\mathrm{r}, \mathrm{sec}}$ was predicted (eq. 1) to be 46.2 and $50.4 \mathrm{ml} / \mathrm{min}$, respectively. When corrected for OCT2 plasma membrane expression in HEK293 and MDCKII cells, the predicted metformin $\mathrm{CL}_{\mathrm{r}, \mathrm{sec}}$ improved to 153.0 and $97.7 \mathrm{ml} / \mathrm{min}$ respectively (Table 1 ). When this predicted metformin $\mathrm{CL}_{\mathrm{r}, \mathrm{sec}}$ $(\mathrm{ml} / \mathrm{min})$ was further corrected for the membrane potential difference between OCT2-expressing cells and the renal epithelial cells, the predicted metformin $\mathrm{CL}_{\mathrm{r}, \mathrm{sec}}$ improved to an average value of $250.7 \mathrm{ml} / \mathrm{min}$ (Table 1), a value lower than the observed geometric mean of $\mathrm{CL}_{\mathrm{r}, \mathrm{sec}}$ but within the observed range $(215-643 \mathrm{ml} / \mathrm{min})$.

\section{Discussion}

To predict the clearance of a drug when transporters are involved, it is important that the plasma membrane expression of the transporter(s) be used to scale in vitro transport clearance to in vivo. Therefore, we optimized a cell-surface biotinylation method to determine the percent of expression of a transporter on the plasma membrane (Kumar et al., 2017). The use of this optimized biotinylation method (Kumar et al., 2017) showed that $\leq 52 \%$ of OCT2 is expressed in the plasma membrane of OCT2-expressing HEK293 and MDCKII cells (Fig. 1B). We confirmed that this result was not due to sulfo-NHS-SS-biotin concentration being limiting (data not shown).

Metformin is primarily cleared $(\sim 70 \%)$ by active renal secretion $\left(\mathrm{CL}_{\mathrm{r}, \mathrm{sec}}\right)$ mediated exclusively by OCT2 located in the basolateral membrane of the proximal tubule epithelial cells (Burt et al., 2016). Then, it is effluxed into the renal tubule by the apical MATE1 and MATE2-K. Moreover, OCT2-mediated uptake of metformin (from the plasma) appears to be the rate-determining step in metformin's $\mathrm{CL}_{\mathrm{r}, \mathrm{sec}}$. Human studies have shown that inhibition of OCT2 by dolutegravir (50 $\mathrm{mg}$, twice daily for 7 days) increases metformin plasma AUC to a larger extent (145\%) than inhibition of both MATE1 and MATE2-K, by a $50 \mathrm{mg}$ oral dose of pyrimethamine (35\%; (Song et al., 2016; Kusuhara et al., 2011). Dolutegravir does not inhibit MATE1 and MATE2-K at doses used (Song et al., 2016) and pyrimethamine is a more potent inhibitor of MATE1 and MATE2-K ( $\left.\mathrm{IC}_{50}: 0.1 \mu \mathrm{M}\right)$ than OCT2 $\left(\mathrm{IC}_{50}: 4.8 \mu \mathrm{M}\right)$.

Although the involvement of other transporters in metformin $\mathrm{CL}_{\mathrm{r}, \mathrm{sec}}$ cannot be discounted, based on the above data, it is reasonable to assume that OCT2 is the rate-determining step in $\mathrm{CL}_{\mathrm{r}, \mathrm{sec}}$ of metformin. Were this is the case, as described by us (Patilea-Vrana and Unadkat, 2016), the renal secretory clearance of metformin will be determined only by its OCT2-mediated clearance. Thus, the renal secretory clearance of metformin should be well-predicted by the uptake clearance of metformin by OCT2-expressing cells, provided this uptake clearance is scaled to that in vivo by the difference in OCT 2 expression in the cells versus kidney cortex. When we assumed that $100 \%$ of OCT2 was located in the plasma membrane of nonpolarized HEK293 and polarized MDCKII cells, the in vivo $\mathrm{CL}_{\mathrm{r} \text {,sec }}$ of metformin was underpredicted [ $\sim 50 \mathrm{ml} / \mathrm{min}$ vs. 415 (range 215-643) $\mathrm{ml} / \mathrm{min}$ ] by about eightfold. When this IVIVE was corrected for the plasma membrane expression of OCT2, the prediction of $\mathrm{CL}_{\mathrm{r}, \mathrm{sec}}$ of metformin improved markedly, but was still lower (153.0 and $97.7 \mathrm{ml} / \mathrm{min}$ in OCT2-HEK293 and MDCKII cells, respectively, Table 1) than its in vivo secretory $\mathrm{CL}_{\mathrm{r}, \mathrm{sec}}$.

For accurate IVIVE of the clearance of a drug, the cell line must replicate the mechanism of transport in vivo. Based on literature data, this is not the case here. OCT2 transport activity is driven by the negative resting membrane potential of the cell. The resting membrane potential of the human renal epithelial cells is $-70 \mathrm{mV}$ (Wright and Dantzler, 2004) while for HEK293 and MDCKII cells it is -20 to $-35 \mathrm{mV}$ (Condreay et al., 2006; Hsu et al., 2010) and -20 to $-50 \mathrm{mV}$, respectively (Westphale et al., 1992; Lang and Paulmichl, 1995).
Correcting for this difference in membrane potential between OCT2expressing cells and renal epithelial cells improved our prediction of metformin $\mathrm{CL}_{\mathrm{r} \text {,sec }}(250.7 \mathrm{ml} / \mathrm{min})$ and resulted in a value within the range observed in vivo (215-643 $\mathrm{ml} / \mathrm{min}$; mean $415 \mathrm{ml} / \mathrm{min})$.

An interesting question that arises from our data is what is the percent of plasma membrane expression of OCT2 in kidney epithelial cells? Immunolocalization data suggest that OCT 2 is predominately located on the plasma membrane of the kidney epithelial cells (Fisel et al., 2016). Unfortunately, this question cannot be addressed by biotinylation without first culturing the cells. Therefore, it will be interesting in the future to determine the plasma membrane expression of OCT2 in primary kidney epithelial cells. Nevertheless, if less than $100 \%$ of OCT2 were expressed in the plasma membrane of these cells, the above IVIVE would be even more discrepant. Therefore, assuming that OCT2 in kidney epithelial cells is $100 \%$ expressed in the plasma membrane is not a reason for the underprediction of the in vivo metformin $\mathrm{CL}_{\mathrm{r}, \mathrm{sec}}$.

Many groups have used primary cells (e.g., human/rat hepatocytes) and empirical scaling factors (Jones et al., 2012; Zou et al., 2013; Izumi et al., 2017) to predict hepatobiliary clearance of drugs. Such methods lack mechanistic insight and therefore may not necessarily apply to a new molecular entity. By incorporating mechanisms of transport and quantitative proteomics to account for the difference in expression of transporters between hepatocytes and liver tissue, such IVIVE has been shown to be successful without using an empirical scaling factor (Bosgra et al., 2014; Ishida et al., 2018). However, this approach has never been applied to the renal secretory clearance of a drug. Here we report the first such successful IVIVE where our prediction falls within the observed metformin $\mathrm{CL}_{\mathrm{r}, \mathrm{sec}}$ values (albeit lower than the mean). Moreover, our data highlight the importance of utilizing cells that mimic the mechanism(s) of transport of drugs in vivo as well as proteomics to quantify plasma membrane expression of transporters to conduct IVIVE of transporter-mediated clearance of a drug.

\section{Authorship Contributions}

Participated in research design: Kumar, Yin, Prasad, Wang, Unadkat. Conducted experiments: Kumar, Yin, Billington.

Contributed new reagents or analytic tools: Yin, Billington, Brown, Wang. Performed data analysis: Kumar, Yin, Prasad, Wang, Unadkat.

Wrote or contributed to the writing of the manuscript: Kumar, Yin, Billington, Prasad, Brown, Wang, Unadkat.

\section{References}

Bosgra S, van de Steeg E, Vlaming ML, Verhoeckx KC, Huisman MT, Verwei M, and Wortelboer HM (2014) Predicting carrier-mediated hepatic disposition of rosuvastatin in man by scaling from individual transfected cell-lines in vitro using absolute transporter protein quantification and PBPK modeling. Eur J Pharm Sci 65:156-166.

Bouchet LG, Bolch WE, Blanco HP, Wessels BW, Siegel JA, Rajon DA, Clairand I, and Sgouros G (2003) MIRD Pamphlet No 19: absorbed fractions and radionuclide S values for six agedependent multiregion models of the kidney. J Nucl Med 44:1113-1147.

Burt HJ, Neuhoff S, Almond L, Gaohua L, Harwood MD, Jamei M, Rostami-Hodjegan A, Tucker GT, and Rowland-Yeo K (2016) Metformin and cimetidine: physiologically based pharmacokinetic modelling to investigate transporter mediated drug-drug interactions. Eur J Pharm Sci 88: $70-82$.

Condreay JP, Ames RS, Hassan NJ, Kost TA, Merrihew RV, Mossakowska DE, Pountney DJ, and Romanos MA (2006) Baculoviruses and mammalian cell-based assays for drug screening. Adv Virus Res 68:255-286.

Dave RA and Morris ME (2015) Quantitative structure-pharmacokinetic relationships for the prediction of renal clearance in humans. Drug Metab Dispos 43:73-81.

Fisel P, Schaeffeler E, and Schwab M (2016) DNA methylation of ADME genes. Clin Pharmacol Ther 99:512-527.

Hsu K, Han J, Shinlapawittayatorn K, Deschenes I, and Marbán E (2010) Membrane potentia depolarization as a triggering mechanism for Vpu-mediated HIV-1 release. Biophys $J$ 99: $1718-1725$.

Ishida K, Ullah M, Tóth B, Juhasz V, and Unadkat JD (2018) Successful prediction of in vivo hepatobiliary clearances and hepatic concentrations of rosuvastatin using sandwich-cultured rat hepatocytes, transporter-expressing cell lines, and quantitative proteomics. Drug Metab Dispos 46:66-74.

Izumi S, Nozaki Y, Komori T, Takenaka O, Maeda K, Kusuhara H, and Sugiyama Y (2017) Comparison of the predictability of human hepatic clearance for organic anion transporting polypeptide substrate drugs between different in vitro-in vivo extrapolation approaches. J Pharm Sci 106:2678-2687. 
Jones HM, Barton HA, Lai Y, Bi YA, Kimoto E, Kempshall S, Tate SC, El-Kattan A, Houston JB, Galetin A, et al. (2012) Mechanistic pharmacokinetic modeling for the prediction of transportermediated disposition in humans from sandwich culture human hepatocyte data. Drug Metab Dispos 40:1007-1017.

Koepsell H and Keller T (2016) Functional properties of organic cation transporter OCT1, binding of substrates and inhibitors, and presumed transport mechanism, in Organic Cation Transporters: Integration of Physiology, Pathology, and Pharmacology (Ciarimboli G, Gautron S, and Schlatter E eds) pp 49-72, Springer International Publishing, Cham, Switzerland.

Kumar V, Nguyen TB, Tóth B, Juhasz V, and Unadkat JD (2017) Optimization and application of a biotinylation method for quantification of plasma membrane expression of transporters in cells. AAPS J 19:1377-1386.

Kusuhara H, Ito S, Kumagai Y, Jiang M, Shiroshita T, Moriyama Y, Inoue K, Yuasa H, and Sugiyama Y (2011) Effects of a MATE protein inhibitor, pyrimethamine, on the renal elimination of metformin at oral microdose and at therapeutic dose in healthy subjects. Clin Pharmacol Ther 89:837-844.

Lang F and Paulmichl M (1995) Properties and regulation of ion channels in MDCK cells. Kidney Int 48:1200-1205.

Paine SW, Ménochet K, Denton R, McGinnity DF, and Riley RJ (2011) Prediction of human renal clearance from preclinical species for a diverse set of drugs that exhibit both active secretion and net reabsorption. Drug Metab Dispos 39:1008-1013.

Patilea-Vrana G and Unadkat JD (2016) Transport vs. metabolism: what determines the pharmacokinetics and pharmacodynamics of drugs? Insights from the extended clearance model. Clin Pharmacol Ther 100:413-418.

Prasad B, Johnson K, Billington S, Lee C, Chung GW, Brown CD, Kelly EJ, Himmelfarb J, and Unadkat JD (2016) Abundance of drug transporters in the human kidney cortex as quantified by quantitative targeted proteomics. Drug Metab Dispos 44:1920-1924.
Song IH, Zong J, Borland J, Jerva F, Wynne B, Zamek-Gliszczynski MJ, Humphreys JE, Bowers GD, and Choukour M (2016) The effect of dolutegravir on the pharmacokinetics of metformin in healthy subjects. J Acquir Immune Defic Syndr 72:400-407.

Vildhede A, Mateus A, Khan EK, Lai Y, Karlgren M, Artursson P, and Kjellsson MC (2016) Mechanistic modeling of pitavastatin disposition in sandwich-cultured human hepatocytes: a proteomics-informed bottom-up approach. Drug Metab Dispos 44:505-516.

Westphale HJ, Wojnowski L, Schwab A, and Oberleithner H (1992) Spontaneous membrane potential oscillations in Madin-Darby canine kidney cells transformed by alkaline stress. Pflugers Arch 421:218-223.

Wright SH and Dantzler WH (2004) Molecular and cellular physiology of renal organic cation and anion transport. Physiol Rev 84:987-1049.

Yin J, Duan H, Shirasaka Y, Prasad B, and Wang J (2015) Atenolol renal secretion is mediated by human organic cation transporter 2 and multidrug and toxin extrusion proteins. Drug Metab Dispos 43:1872-1881.

Yin J, Duan H, and Wang J (2016) Impact of substrate-dependent inhibition on renal organic cation transporters hOCT2 and hMATE1/2-K-mediated drug transport and intracellular accumulation. $J$ Pharmacol Exp Ther 359:401-410.

Zou P, Liu X, Wong S, Feng MR, and Liederer BM (2013) Comparison of in vitro-in vivo extrapolation of biliary clearance using an empirical scaling factor versus transport-based scaling factors in sandwich-cultured rat hepatocytes. J Pharm Sci 102:2837-2850.

Address correspondence to: Jashvant D. Unadkat, Department of Pharmaceutics, University of Washington, Seattle, P.O. Box 357610, WA 98195. E-mail: jash@ uw.edu 